\title{
Hérnia de Petit bilateral espontânea
}

\section{Spontaneous bilateral Petit hernia}

\author{
Rodrigo Dias Fontoura 1; Emerson Silveira de Araúo 1; Gustavo Alves de Oliveiraz; Deolindo Sarmenghi Filho, ACBC-ES 3 ; Mitre \\ KALIL, TCBC-ES 4
}

\section{INTRODUÇÃO}

A $s$ hérnias lombares (lomboilíacas) e dorsais (lombocostoabdominais) correspondem a menos de $1 \%$ das hérnias da parede abdominal ${ }^{1}$. O conteúdo herniário pode ser, gordura pré-peritonial, retroperitonial ou uma víscera abdominal, contidos no saco herniário, que faz protusão através pontos fracos e orificios existentes na aponeurose da musculatura dos espaços lombocostoabdominal, abaixo da $12^{\text {a }}$ costela (GrynfeltLesshaft) e do lombo-ilíaco (Petit)2.

As hérnias lombares podem ser: espontâneas (55\%), traumáticas (26\%) e congênitas $(19 \%)^{1}$. O diagnóstico, na maioria das vezes, é feito através da história clínica e exame físico ${ }^{1,3}$. O encarceramento ocorre em $25 \%$ dos casos e o estrangulamento em $8 \%{ }^{4}$, sendo a cirurgia por via convencional a mais indicada e adequada.

O objetivo desse artigo é relatar um caso de hérnia de Petit espontânea bilateral tratada por via convencional sem o uso de prótese.

\section{RELATO DO CASO}

Paciente de 69 anos, masculino, pardo, natural de Cachoeiro de Itapemirim-ES, procurou o Serviço de Clínica Cirúrgica da Santa Casa de Misericórdia de VitóriaES, com queixa de massa indolor e de crescimento progressivo na região lombar direita há seis anos. Não apresentava comorbidades, história de trauma local ou cirurgia prévia.

Ao exame físico apresentava-se em bom estado geral, lúcido e orientado, normocorado, normohidratado, eucárdico, eupneico, afebril, IMC=22,3, abdome atípico, indolor, sem visceromegalias ou massas palpáveis. Presença de tumorações lombares redutíveis, indolores à palpação, com diâmetros de $10 \mathrm{~cm}$ à direita e $4 \mathrm{~cm}$ à esquerda (Figura 1).

O paciente foi submetido à herniorrafia lombar bilateral através de incisões tranversais de $+/-6 \mathrm{~cm}$, com dissecção, abertura dos sacos herniários, recondução de seus conteúdos à cavidade e reforço músculoaponeurótico em dois planos de sutura com fio de nylon 0 , incluindo os músculos oblíquo interno, externo e parte do grande dorsal (Figura 2). Teve boa evolução pós-operatória, tendo alta hospitalar no dia seguinte. Encontra-se em acompanhamento ambulatorial e sem queixas.

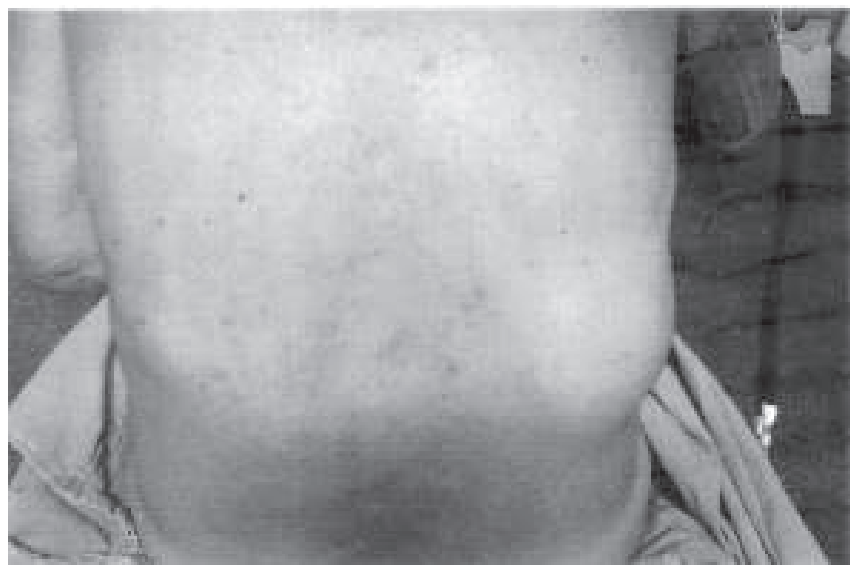

Figura 1 - Tumefações lombo-ilíacas - Hérnias de Petit.

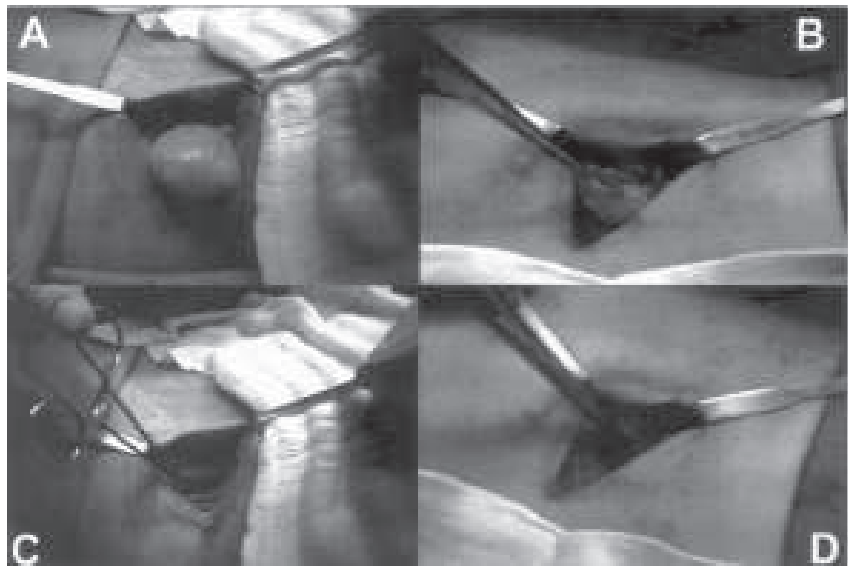

Figura 2 - Direita $(A$ e $C$ ) e Esquerda (B e D) Hérnias de Petit.

Trabalho realizado no Departamento de Clínica Cirúrgica da Escola Superior de Ciências da Santa Casa de Misericórdia de Vitória, ES EMESCAM.

1. Ex. Residentes de Cirurgia Geral da Santa Casa de Misericórdia de Vitória-ES; 2. Cirurgião da Santa Casa de Misericórdia de Vitória-ES; 3 Cirurgião Geral do Hospital Evangélico de Vila Velha -ES; 4. Professor Associado Doutor da Disciplina de Fundamentos da Cirurgia da Escola Superior de Ciências da Santa Casa de Misericórdia - EMESCAM e Titular de Técnica Operatória e Clínica Cirúrgica da Faculdade de Medicina da UNIVIX - ES 


\section{DISCUSSÃO}

Na literatura pudemos verificar aproximadamente 300 casos de hérnias lombares traumáticas unilaterais. Os relatos de hérnias lombares bilaterais encontrados são aquelas secundárias à trauma lombar ou cirurgia prévia, sendo raro a de Petit bilateral e espontânea.

As hérnias lombares inferiores ou de Petit são menos frequentes que as superiores ou de Grynfelt ${ }^{2}$, acometendo a mulher jovem e raramente constituída por saco herniário' (verdadeiras).

A hérnia lombar adquirida é quase sempre unilateral e tem como fatores etiopatogênicos, o enfraquecimento parietal, tosse, obesidade e esforço físico repetido'.
A tumefação normalmente se apresenta como uma massa semicircular, indolor, redutível na região lombar como aqui evidenciado.

A escolha da técnica depende da experiência do cirurgião, das condições da camada músculoaponeurótica do paciente e do diâmetro do anel herniário. Neste paciente os tecidos estavam espessos e resistentes, o que propiciou dois planos de sutura firmes.

Moreno et al. relataram as vantagens da via laparoscópica sobre a convencional ${ }^{5}$. Somos partidários da via convencional, por ser esta a mais adequada na restauração anatômica da parede abdominal.

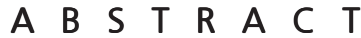

Petit's lumbar hernia is an uncommon defect of the posterior abdominal wall that represents less than $1 \%$ of all abdominal wall hernias. It is more often unilateral and founded in young females, rarely containing a real herniated sac. There are two different approaches to repair: laparoscopy and open surgery. The goal of this article is to report one case of spontaneous bilateral lumbar Petit's hernia treated with open surgery.

Key words: Low back pain. Hernia. Therapeutic/surgery.

\section{REFERÊNCIAS}

1. Malangoni MA, Gagliardi RJ. Hérnias. In: Townsend CM, Beauchamp RD, Evers BM, Mattox KL, editores. Sabiston - Tratado de cirurgia: A base biológica da prática cirúrgica moderna. $17^{a}$ ed. Rio de Janeiro: Elsevier; 2005. p.1199-217.

2. Chacon JP, Goffi FS. Parede abdominal, fígado, vias biliares, pâncreas e baço. São Paulo: Sarvier; 1979. Hérnia lombar; p.35-48.

3. Kalil M, Man Nato CH. Técnica cirúrgica. Vitória/ES: Unimed Vitória; 1980.

4. Zhou X, Nve JO, Chen G. Lumbar hernia: clinical analysis of 11 cases. Hernia 2004; 8(3):260-3.

5. Moreno-Egea A, Torralba JA, Morales G, Fernández T, Guzmán $P$, Hita $G$, et al. Laparoscopic repair of secondary lumbar hernias: open vs. laparoscopic surgery. A prospective, nonrandomized study. Cir Esp 2005; 77(3):159-62.
Recebido em 01/03/2007

Aceito para publicação em 10/04/2007

Conflito de interesse: nenhum

Fonte de financiamento: nenhuma

Como citar este artigo:

Fontoura RD, Oliveira GA, Araújo ES, Sarmenghi Filho D, Kalil M. Hérnia de petit bilateral espontânea. Rev Col Bras Cir. [periódico na Internet] 2011; 38(5). Disponível em URL: http://www.scielo.br/rcbc

Endereço para correspondência:

Prof. Mitre Kalil, TCBC.

E-mail: mitre.kalil@emescam.br 